\title{
O CONTO DA AIA: UMA LEITURA MULTIDISCIPLINAR
}

\author{
EL CUENTO DE LA CRIADA: UNA LECTURA MULTIDISCIPLINARIA
}

\section{THE HANDMAID'S TALE: A MULTIDISCIPLINARY READING}

\author{
Eloísa Cecília Dias Martins \\ Universidade do Estado da Bahia UNEB. Brasil \\ Elizeu Pinheiro da Cruz \\ Universidade do Estado da Bahia - UNEB. Brasil \\ Sidnay Fernandes dos Santos \\ Universidade do Estado da Bahia - UNEB. Brasil
}

\begin{abstract}
RESUMO
Este texto apresenta uma análise do romance O Conto da Aia, Margaret Atwood, e a sua versão cinematográfica no formato de série como possibilidade de reflexão multidisciplinar de questões como relações de gênero, parentesco e a dicotomia natureza-cultura para refletir sobre os contextos políticos brasileiro e estadunidense contemporâneos. No Conto, a República de Gilead fundada em um fundamentalismo religioso após um golpe de estado, é constituída por relações de parentesco exclusivamente heterossexual que circunscrevem gênero e sexualidade à dimensão de uma natureza fixa, tendo como origem um Deus criador. A obra de Atwood traz temas das agendas feministas, discussões ecológicas, religiosas, políticas, direitos de minorias, gênero, dentre outros, que estiveram e estão no centro das agendas eleitorais nos últimos anos e, por isso, não se pode estar alheio a elas. Ao engajar a análise na problematização de opressões contra as minorias do tempo presente, os autores deste texto enfrentam as suas correlações com as opressões da República de Gilead.
\end{abstract}

Palavras-Chave: Distopia. Discurso. Gênero. Sexualidade. O Conto da Aia.

\section{RESUMEN}

Este texto presenta un análisis de la novela "El cuento de la criada", Margaret Atwood, y su versión de la película en el formato de serie como la posibilidad de reflexión multidisciplinaria sobre temas tales como las relaciones de género, el parentesco, la dicotomía entre naturaleza y cultura, para reflexionar sobre los contextos políticos brasileños y estadounidenses contemporáneos. En el cuento, la República de Gilead fundada en un fundamentalismo religioso después de un golpe de estado, se compone de relaciones de parentesco 
exclusivamente heterosexuales que delimitan el género y la sexualidad a la dimensión de una naturaleza fija, teniendo como origen un Dios creador.El trabajo de Atwood trae temas de las agendas feministas, ecológicas, religiosas, políticas, derechos de las minorías, género, dentre otros, que han estado y están en el centro de las agendas electorales en los últimos años y, por lo tanto, no se les puede ignorar que han sido y son el centro de la agenda electoral en los últimos años $\mathrm{y}$, por lo tanto, no puede ser ajena a ellas. Al realizar el análisis para problematizar las opresiones contra las minorías de la actualidad, los autores de este texto enfrentan sus correlaciones con las opresiones de la República de Gilead.

Palabras clave: Distopía. Discurso. Género. Sexualidad. Cuento de la Criada.

\begin{abstract}
This text presents an analysis of the novel "The Handmaid's Tale", Margaret Atwood, and its cinematographic version in series format as a possibility for multidisciplinary reflection on issues such as gender relations, kinship and the nature-culture dichotomy to reflect on contemporary Brazilian and American political context. In the story, the Republic of Gilead, founded on a religious fundamentalism after a coup, is made up of exclusively heterosexual relationships that circumscribe gender and sexuality to the dimension of a fixed nature, originating from a creator God. Atwood's work brings themes from feminist agendas, ecological, religious, political, minority rights, gender, among others, that have been and are at the center of electoral agendas in recent years and, therefore, cannot be oblivious to them. By engaging the analysis in problematizing oppressions against the minorities of the present time, the authors of this text face their correlations with the oppressions of the Republic of Gilead.
\end{abstract}

Keywords: Dystopia. Speech. Genre. Sexuality. The Handmaid's Tale.

\title{
1 No tempo das catástrofes
}

Em dezembro de 2019, foi identificado na China um agente infeccioso capaz de causar um surto de pneumonia respiratória em humanos. Da família coronavírus, este agente possivelmente circulou de animais não humanos - ao que parece, até então, assintomáticos para os animais humanos, causando nestes últimos, mas não em todos (humanos também podem ser assintomáticos), uma doença nomeada de COVID-19 que passou a circular pelos quatro cantos do mundo, tornando-se uma pandemia. Já em março de 2020, o Portal Gl ${ }^{i}$ publicou um dado elaborado pela universidade norte-americana Johns Hopkins: mais de dez mil pessoas em todo mundo morreram acometidas com a COVID-19. Estaríamos diante de uma catástrofe capaz de, como coloca a música italiana de 1982 que ganhou versões em diversos países, inclusive no Brasil, pela Banda Rádio Táxi e, posteriormente, pela Banda Eva ${ }^{\mathrm{ii}}$, levar a espécie humana ao fim da sua aventura na Terra? Ironicamente, até o final de março de 2020, a Itália perdeu milhares de humanos por conta da COVID-19. 
O novo coronavírus tem feito até aqueles que refutam a mudança climática - e as suas consequências como o efeito estufa - a reverem os seus posicionamentos, ainda que o crescimento dos óbitos não tenha sido o suficiente para convencer a todos que não se trata de "uma fantasia", conforme classificou o presidente da República Federativa do Brasil, Jair Bolsonaro, incapaz de reconhecer a gravidade da situação, não apenas para os humanos, alvos exclusivos das políticas mundiais de saúde, mas também para os diversos seres que habitam as florestas, os oceanos e os múltiplos lugares que constituem a biota do planeta. Há uma ameaça que alcança a todos, sem distinção, e certamente os que já viviam as suas vidas como alvos de diversas opressões, de gênero, de raça e de sexualidade, para dizer três delas, agora têm os seus sofrimentos acentuados e mais uma doença para a sua coleção (zika ${ }^{\text {iii }}$, chicungunha, dengue, malária, COVID-19), jamais escolhida.

Judith Butler (2019), filósofa feminista que, desde "Problemas de gênero: feminismo e subversão da identidade", livro que teve a primeira edição publicada da década de 1990, já nos alertava para o equívoco da essencialização da identidade, ponderou recentemente ${ }^{\text {iv }}$ que o coronavírus não discrimina, a ameaça é para todos, mas que humanos se encarregarão de fazer a discriminação com os mesmos critérios de sempre: nacionalismo, racismo, xenofobia e capitalismo.

No Brasil, as elites se apressam para definir quem poderá ficar vivo. "Vacinaremos a população em drive-thrus", gritam os favorecidos em grupos de WhatsApp, assim não precisarão viver com os não eleitos nem assistir aos seus fracassos. Xenofobia, racismo, sexíssimo, LGBTfobia, preconceito de classe e outras opressões estão encapsulados em milhares de coronavírus ávidos a matar corpos que não importam para as elites. A cegueira é o véu da tranquilidade de quem pode ficar dentro de casa esperando um novo mundo para si, ainda que devastado, quem sabe um novo regime político completamente afinado às pautas de ódio que reúnem homens em grupos políticos que fazem Adolf Hitler parecer um homem deste tempo. Posteriormente, chamarão os liberais, os conservadores e os liberais conservadores para limpar e decorar os espaços com "um dólar baratinho" [!].

Um flanelinha "bateu a real" nos grupos de WhatsApp: "Já peguei zika, chicungunha, dengue. Se eu pegar o coronavirus, o corpo não aguenta”. Ele "pegou a visão" e se trancou em casa, até quando conseguirá, não se sabe, precisará fazer “os corre" ${ }^{\mathrm{vi}}$ necessários à existência de quem trabalha na informalidade, sem as garantias sociais de muitos daqueles que estão trancados em casa esperando a pandemia passar. E a Escola de Samba Mangueira, do Rio de Revista RBBA $\mid$ Revista Binacional Brasil Argentina 
Janeiro, em seu carnaval de 2020, já havia convocado a favela para "pegar a visão" sobre a inexistência de futuro sem partilha e a inexistência de Messias de arma na mão ${ }^{\mathrm{vii}}$.

A música de Giancarlo Bigazzi e Humberto Tozzi indica que a loucura humana destruirá os próprios humanos. Dito de outro modo, destruirá a si própria, a "loucura" seria então autofágica. Deixando de lado a dicotomia razão-loucura e após todo este palavrório sobre a COVID-19 ${ }^{\text {viii }}$, queremos aqui, de modo um tanto ousado, nos debruçar sobre um texto literário (O Conto da Aia) e a sua versão cinematográfica como possibilidade de reflexão multidisciplinar de questões como relações de gênero, parentesco e a dicotomia naturezacultura para dizer algo sobre os contextos políticos brasileiro e estadunidense contemporâneos, marcados por distopias. Analisaremos, a seguir, o romance o Conto da Aia (The handmaid's tale) e a sua versão cinematográfica no formato série a fim de fazer uma intervenção "no tempo das catástrofes", tomando de empréstimo o título do livro de Isabelle Stengers ${ }^{\mathrm{ix}}$ (2015), sobre conjunturas políticas do mundo ocidental. Stengers propõe no seu livro "No tempo das catástrofes" uma intervenção, similar àquilo que se experimenta em um debate quando alguém toma a palavra e faz uma intervenção, provocando uma pausa. Posteriormente, os que presenciaram a pausa mostrar-se-ão tocados. Uma intervenção reflexiva capaz de fazer outros pensarem e agirem. Em consonância com esta perspectiva de intervenção, almejamos que este seja uma intervenção sobre o conservadorismo - quase um deboche - capaz de fazer pensar e fazer agir os nossos leitores. "Intervir requer certa brevidade, pois não se trata de convencer, e sim de transmitir para 'aqueles a quem se pode afetar' o que nos faz pensar, sentir, imaginar" (STENGERS, 2015, p. 5)

Antes de seguirmos adiante, faz-se necessário abrir aqui um rápido parêntese para uma definição de distopia, que é derivada de duas palavras gregas, dus e topos, e, ao pé da letra, significa um lugar doente, ruim, defeituoso ou desfavorável. Ao trazer esse conceito para o nosso campo analítico, compreendemos que uma das características principais dos textos distópicos é a materialização de críticas às tendências, aos comportamentos e aos fenômenos frequentemente marcadas pela presença do autoritarismo, violência física ou psicológica, perda de liberdades individuais e, principalmente, alienação. Assim, as distopias trazem o pesadelo de um futuro ao se maximizar circunstâncias reais do presente (PEREIRA, 2018). 


\section{Conto da Aia}

No ano de 2017, as premiações hollywoodianas fervilhavam ao som do incrível musical “La La Land: Cantando Estações”. Sentados em nossos sofás, acompanhamos o anúncio do Emmy naquela noite de 17 de setembro, aguardando ansiosos pelo anúncio da produção vencedora na categoria série dramática. Naquele ano, a grande aposta era que a grande produção da Netflix The Crown seria a premiada. E, eis que, de repente, fomos surpreendidos: uma série do sistema de streaming Hulu, chamada The Handmaid's Tale (O Conto da Aia), foi a vencedora. E esse não foi o único prêmio. A melhor atriz em série dramática não foi Claire Foy, que interpretou a Rainha Elizabeth II em The Crown, mas sim Elizabeth Moss, a protagonista do Conto da Aia. E as premiações que se seguiram para a equipe do Conto da Aia não pararam por aí: Ann Dowd, melhor atriz coadjuvante; Alexis Bledel, melhor atriz convidada em série dramática; Reed Morano, melhor direção em série dramática; e Bruce Miller, melhor roteiro.

O Conto da Aia foi escrito pela romancista canadense Margaret Atwood, internacionalmente premiada. Publicado em 1985, o romance de Atwood foi recepcionado como um texto distópico. Em 2019, a Globo comprou os direitos de transmissão da série no Brasil e passou a exibi-la no Globoplay, aos seus assinantes.

No romance e na série, por conta das consequências da devastação ambiental, as taxas de fertilidade caíram drasticamente e os Estados Unidos entram em colapso, com conflitos internos e guerras civis. É, nesse cenário, que um movimento cristão chamado "Filhos de Jacó" matou o Presidente da República e a maior parte dos membros do Congresso e instalou uma nova república chamada Gilead. O novo Governo, de caráter teocrático, teve como primeiras ações: pôr fim aos direitos das mulheres e, além disso, dividir toda a população em castas que desempenham, na trama narrativa, papéis muito bem definidos. Parentesco e relações de gênero são cruciais na organização do Regime.

O romance é narrado pela personagem Aia Offred que, na série, é interpretada por Elisabeth Moss e a história segue sua trajetória desde quando Offred é retirada do convívio familiar e submetida a treinamento por mulheres chamadas de Tias até seu serviço na casa de Fred Waterford, um dos comandantes do novo Regime.

O Conto da Aia imbrica acontecimentos do passado e do presente para dar contorno à trama, enredando leitores e telespectadores em correlações com os acontecimentos do tempo presente: xenofobia, racismo, sexíssimo, preconceito de classe e outras opressões desnudadas também pela COVID-19. Portanto, se o romance e a série jogam com os tempos para construir Revista RBBA $\mid$ Revista Binacional Brasil Argentina 
a narrativa, também nós o faremos para analisar a distopia narrada, problematizando a relação entre opressão e sistemas políticos.

E, para isso, consideramos a articulação de materialidades ficcionais - o livro e a obra televisiva O Conto de Aia - com textualizações ditas não ficcionais, muitas delas presentes na seção de brutalidades de noticiários nacionais e internacionais. Nesse sentido, tomamos a noção de interdiscursividade tal como apresentada por Maingueneau (2007): um texto, ao aparecer, já emerge na relação com outros textos, com outros discursos. Uma leitura multidisciplinar situa ainda mais essa noção e corresponde à proposta deste texto.

\section{Uma história em castas}

Na narrativa ficcional, o novo Governo é instaurado a partir de um golpe de estado, com muitos elementos semelhantes ao golpe contra a Presidenta Dilma Rousself; sexíssimo, machismo, fanatismo religioso e conservadorismo são alguns dos pontos semelhantes. No Conto, a protagonista relata o golpe que fundou Gilead como resultado de uma catástrofe que culminou em um decreto de emergência do Exército e consequente suspensão da Constituição. A culpa foi colocada nos mulçumanos [nacionalismo e xenofobia].

O Exército que assumiu a intervenção não era parte das antigas forças nacionais americanas, mas uma organização paralela, uma força clandestina que iniciou uma segunda etapa da tomada do poder. A protagonista é dispensada do emprego na biblioteca da cidade após decreto que proibiu as mulheres de trabalharem. E não parou por aí. As contas bancárias das mulheres e os seus bens foram todos transferidos para os maridos ou parentes homens mais próximos. As dissimulações dos eufemismos sobre as tomadas dos regimes democráticos na América Latina e a crueza do totalitarismo da tomada do poder no Conto de Atwood estão, de certo modo, presentificadas no enunciado "Deus acima de todos", que se tornou um mantra de partidos de extrema direita do mundo avesso às minorias políticas.

No Conto da Aia, as mulheres foram proibidas de ler e de exercer as liberdades. Quando transgrediam três vezes às regras do Regime, eram punidas com a amputação de uma das mãos. E, obviamente, que as restrições da autonomia e do conhecimento aplicadas às mulheres tinham não apenas objetivos religiosos e ideológicos, mas também pragmáticos. Com a baixa natalidade, as mulheres desempenhariam papéis centrais no Regime.

É importante ressaltar que, na trama narrativa, antes da instauração do novo Regime, a humanidade já havia submetido o planeta a diversos impactos ambientais como vazamentos e Revista RBBA $\quad$ Revista Binacional Brasil Argentina 
envenenamentos radioativos, contaminação de cursos d'agua por moléculas tóxicas, agrotóxicos, dentre outros. Emergências sanitárias e ambientais fizeram o risco aparecer para todos e reivindicavam uma reorganização do poder político. Os idealizadores da República de Gilead "sequestraram" essa versão narrativa para nela "colar" suas ideologias totalitaristas e opressoras, cujo cerne era conteúdos morais sem se preocuparem com a subversão de uma ética transacional.

Usos de medicamentos, cirurgias de laqueadura e problemas ambientais tornaram grande parte da população estéril. Pelas palavras de Offred, a protagonista, o interlocutor (leitor/telespectador) tem conhecimento sobre regras e estatísticas do Regime, entre as estatísticas, a cada quatro mulheres, apenas uma poderia engravidar.

Houve uma época em que o ar ficou carregado demais de substâncias químicas, raios, radiação, a água enxameava com moléculas tóxicas, tudo isso leva anos para pôr em ordem, e enquanto isso elas penetram em seu corpo, se acumulam nas células adiposas do corpo. Quem sabe, sua própria carne pode estar poluída, suja como uma praia onde houve um derramamento de petróleo, morte certa para os pássaros marítimos e bebês ainda por nascer. Talvez um abutre morresse se comesse você. (ATWOOD, 2017, p.137)

Os humanos de Gilead não atribuíam a infertilidade às questões ambientais e farmacológicas, mas sim às próprias mulheres. Em um dos diálogos relatados no livro, Serena Joy, a esposa do comandante Fred e uma das idealizadoras do Regime, ao lado do esposo, comenta com a Aia a respeito dessa infertilidade, questionando que talvez a infertilidade fosse do homem. A Aia então repreende Serena: "São só as mulheres que não podem, que permanecem teimosamente fechadas, danificadas, defeituosas" (ATWOOD, 2017, p.243).

Em outro evento da narrativa, em conversa com o comandante, quando este utiliza a palavra estéril, a Aia Offred quase engasga de espanto. E pensa: "existem apenas mulheres que são fecundas e mulheres que são estéreis, essa é a lei” (ATWOOD, 2017, p.75).

Na República de Gilead, existem as castas masculinas e femininas. Os membros de cada uma delas usam roupas da mesma cor, que as definem. Entre as castas masculinas, destaca-se a casta dos Comandantes, que são homens ricos, eles cuidam das leis, da diplomacia e da política. Têm direito a esposas e, caso estas não seja fértiis, podem ter uma Aia, para, por meio dela, cumprir seu papel de reprodutor. Numa casta inferior à casta do comandante, estão os anjos e soldados de nível mais alto, eles usam uniformes na cor preta e podem também ter esposa e Aias. De uniforme verde escuro, destaca-se a casta dos guardiões. Estes podem lutar 
nas guerras, são guardas no território da República, não têm direto a uma esposa, mas, caso provem "seu valor" no serviço, podem ser recompensados com uma, que geralmente faz parte da casta das econopessoas ${ }^{\mathrm{x}}$. A casta das Econoesposas engloba mulheres pobres que vivem à margem social, são obrigadas a professar a fé de Gilead, usam roupas listradas nas cores azul, vermelho e verde, que sinalizam as possibilidades de desempenhar as funções de todas as outras castas.

Há uma casta chamada "Os olhos de Deus", ou simplesmente "Os Olhos". Trata-se de uma casta espiã e seus membros vivem no anonimato. Qualquer membro, seja masculino ou feminino ou pertencente a qualquer uma outra casta, pode integrar a esta casta, basta ser fiel ao Regime e estar disposto a espionar os demais. Os Olhos podem denunciar até mesmo um comandante, caso esteja cometendo algum ato ilícito que fira as leis de Gilead.

Todas as castas femininas, ainda que uma ou outra tenha algum privilégio, estão totalmente sujeitas às castas masculinas e possuem a liberdade cerceada.

No livro, a esposa do comandante Fred, Serena Joy, pertencente à casta das Esposas, é descrita mais minuciosamente. Pela constituição dessa personagem, é possível compreender o papel da esposa em Gilead: responsável pela administração da casa, jardinagem, tricotagem e monitoramento dos serviços realizados por mulheres das castas das Marthas e das Aias. As esposas se vestem de azul e a escolha por essa cor é motivada pela referência à cor do manto da Virgem Maria. Na obra impressa, Serena Joy é uma das poucas personagens, cuja história de vida anterior à implantação do Regime é apresentada e, mesmo assim, em um breve relato. Seu nome verdadeiro é Pam e foi cantora antes de passar a fazer discursos sobre a santidade do lar e o papel da mulher.

Considerando o contexto do Brasil e estereótipos que são culturalmente atribuídos às mulheres, se Serena Joy tivesse vivido em terras tupiniquins, especificamente no sertão da Bahia, poderia ser conhecida como "Santa do pau oco" por dissimular até o final da segunda temporada da série. A sua correspondente na política brasileira de hoje seria a Deputada Federal Carla Zambelli, que, antes de proferir discursos em defesa da família, de combate à corrupção e contra minorias políticas, para ficar em apenas três da matriz de ódio do bolsonarismo, participou de manifestações do FEM, grupo feminista que surgiu na Ucrânia.

Sobre Serena Joy, a narradora-protagonista Offred diz: 
Seus discursos eram sobre a santidade do lar, sobre como as mulheres deveriam ficar em casa. Ela mesma não ficava, em vez disso, Serena Joy fazia discursos, mas apresentava essa sua falha como um sacrifício que estava fazendo pelo bem de todos. [...]. Ela não faz mais discursos. Tornou-se incapaz de falar. Fica em casa, mas isso não parece lhe fazer bem. Como deve estar furiosa, agora que suas palavras foram levadas a sério. (ATWOOD, 2017, p.58).

A casta das Marthas, por sua vez, é responsável por todo o trabalho de limpeza, organização, alimentação, cuidado das crianças, dentre todos os outros trabalhos domésticos possíveis. As Marthas usam roupas verdes. Na Bíblia cristã, Marta (sem a letra "h" na grafia do nome), personagem muito mais rica do que a sua apropriação pelo Regime, é descrita como uma mulher que se ocupava pelos serviços domésticos.

Então, se aproximou de Jesus e disse: Senhor, não te importas de que minha irmã tenha deixado que eu fique a servir sozinha? Ordena-lhe, pois, que venha ajudar-me. Respondeu-lhe o Senhor: Marta! Marta! Andas inquieta e te preocupas com muitas coisas. Entretanto, pouco é necessário ou mesmo uma só coisa; Maria, pois, escolheu a boa parte, e essa não lhe será tirada. (BÍBLIA SAGRADA, Lucas 10:40-42).

As Marthas, em $O$ Conto da Aia, são as únicas que mantêm uma relação de comunicação entre as outras. Podem sair para fazer compras, são mulheres já velhas, ou inférteis, ou viúvas. Antes de Gilead, foram advogadas, engenheiras, médicas, cientistas, profissões proibidas às mulheres na nova conjuntura. Quando elas se tornam incapazes de trabalhar, são enviadas para as chamadas colônias, lugares de trabalhos forçados, a maioria relacionados a lixo tóxico, e ali morrem. É nessa casta, que inicia o movimento Mayday, a resistência.

A Casta das Tias é a única à qual é permitida a leitura. Não se sabe como surgiram ou como foram escolhidas, mas acredita-se que a extrema fidelidade ao Regime foi um dos critérios. Elas são as responsáveis por treinar a casta das Aias no Centro Vermelho. São extremamente agressivas e, por isto, responsáveis pelas punições das Aias quando estas cometem algum ato contrário ao treinamento recebido. As Tias acompanham os desempenhos das Aias e realizam as inspeções médicas mais simples. Vestem roupas marrons; segundo a autora Margareth Atwood, uma referência aos uniformes nazistas.

Por fim, apresentamos a casta que mais nos interessa: a casta das Aias. As Aias são as mulheres férteis, elas geralmente pertenciam a diferentes religiões, algumas eram homossexuais, outras eram divorciadas ou que tiveram um segundo casamento, dentre outras. 
A protagonista e narradora da história é uma Aia. As mulheres desta Casta são submetidas a um trabalho de alienação, a começar pela perda da própria identidade.

Se, nas Castas das Esposas e das Tias, ainda é possível identificar algumas mulheres por seus nomes, como Serena Joy e Tia Lydia, entre as Aias, isso não é mais possível. O nome da Aia é uma ênfase ao nome do comandante ao qual serve no momento. No caso da protagonista, Offred significa, numa tradução livre, $O f$ - de e Fred, o nome do comandante. Seu nome remete a uma posse: "De Fred". Quando uma Aia sai da casa de um comandante para outra casa de um outro comandante, seu nome é adaptado para informar a nova posse. As Aias não possuem identidade, não podem ser únicas, individuais, o nome que recebem tem a função de alienar a identidade que outrora possuíram, tidas como perigosas pelo Regime. Suas identidades referemse aos seus donos, a relação de propriedade. O nome, como elemento fundamental da individualização, recebido no nascimento, é negado às Aias. Ao tirar a possibilidade de as Aias terem nomes, roubam-nas de si próprias, retiram suas individualidades. No entanto, como estratégia de resistência, as Aias buscam manter vivas, ao menos secretamente, suas identidades anteriores:

Aprendemos a sussurrar quase sem qualquer ruído. Na semiobscuridade podíamos esticar nossos braços, quando as Tias não estavam olhando, e tocar as mãos umas das outras sobre o espaço. Aprendemos a ler lábios, nossas cabeças deitadas coladas às camas, viradas para o lado, observando a boca umas das outras. Dessa maneira trocávamos nomes, de cama em cama: Alma. Janine. Dolores. Moira. June. (ATWOOD, 2017 p12).

As Aias são treinadas nos chamados Centros Vermelhos (Centro Raquel e Leia). O treinamento almeja internalizar as suas funções no Regime e a amar o privilégio de tê-las. No livro, relata-se um momento das Aias no Centro Vermelho, local no qual elas são obrigadas a narrar seus segredos anteriores a fim de que sintam vergonha dos atos anteriormente cometidos. Em uma dessas sessões, uma das Aias, aqui tratada pelo antigo nome, Janine, relata como foi estuprada por uma gangue aos catorze anos, engravidando como consequência e, por isso, realizou um aborto. Após o relato, Tia Helena pergunta:

Mas de quem foi a culpa?, diz tia Helena, levantando um dedo roliço.

Dela, foi dela, foi dela, foi dela, entoamos em uníssono.

Quem os seduziu? Tia Helena sorri radiante, satisfeita conosco.

Ela seduziu. Ela seduziu. Ela seduziu.

Por que Deus permitiu que uma coisa tão terrível acontecesse?

Para lhe ensinar uma lição. Para the ensinar uma lição. Para the ensinar uma lição. (ATWOOD, 2017 p.88).

Revista RBBA Revista Binacional Brasil Argentina 
No final do relato, Janine explode em lágrimas. Naquele momento, a protagonista relata que todas em volta a desprezavam. Tia Helena lhe ensinou uma lição e, na outra semana, Janine estava de novo à frente para novamente fazer seu relato. Nessa ocasião, ela não mais espera as zombarias. Antes de iniciar o depoimento, Janine se culpa, afirma que incitou os estupradores, seduzindo-os. Portanto, sentindo-se culpada, aceita o sofrimento como castigo.

Essas sequências narrativas/discursivas podem ser interpretadas como o ápice para a caracterização, inclusão, de O Conto de Aia como uma obra distópica. Como culpar a vítima pelo estupro? Mas, olhando pesquisas recentes, essa realidade não está apenas no Conto da Aia. Uma pesquisa inédita denominada \#APolíciaPrecisaFalarSobreEstupro, encomendada ao Datafolha pelo Fórum Brasileiro de Segurança Pública (FBSP) ${ }^{\mathrm{xi}}$ e realizada no ano de 2016, apresenta que $42 \%$ dos homens acreditam que o estupro acontece porque as mulheres "não se dão ao respeito" e/ou usam roupas provocantes e sensuais. Ou seja, um, em cada três homens brasileiros, acredita que o estupro é culpa da vítima. O mais assustador é que $32 \%$ das mulheres concordam com essa afirmação (JUSBRASIL, 2016).

Como não mencionar ainda o caso do Promotor de justiça Theodoro Alexandre da Silva Silveira, que, em 2014, no Rio Grande do Sul, humilhou uma vítima de abuso sexual, dizendo que ela era uma pessoa de sorte por não ter mais de dezoito anos, se não ele pediria a prisão preventiva para que ela fosse estuprada novamente na prisão ${ }^{x i i}$.

Em 26 de Setembro de 2017, um homem foi preso em flagrante no Brasil, na cidade de São Paulo, por ter ejaculado em uma mulher dentro de um ônibus que circulava pela Avenida Paulista. $\mathrm{O}$ assunto ganhou diferentes repercussões em redes sociais. Várias postagens diziam que a mulher deveria se sentir honrada, ao passo que foi objeto de desejo desse homem. Por fim, o juiz absolveu o homem. À Revista Carta Capital, ele respondeu com convicção que o homem, ao ejacular na passageira, não foi violento nem ameaçou a vítima e que, portanto, não configurou o crime de estupro (FEITAL et al. 2018).

Como ainda deixar passar despercebida aquela afirmação do hoje Presidente da República Federativa do Brasil, na época ainda deputado, quando, por duas vezes - uma na Tribuna da Câmara dos Deputados e, a outra, em entrevista à emissora RedeTV - afirmou que só não estupraria a deputada Maria do Rosário porque ela não merecia. ${ }^{\text {xiii }}$ Então, para Jair Bolsonaro, há mulheres que merecem ser estupradas. 
Conforme pontuamos até qui, culpar a vítima pelo crime do estupro na esfera da crença da supremacia do gênero masculino não é uma prática exclusiva da República de Gilead. É uma prática que a autora retoma de todos os espaços (lá nos Estados Unidos, aqui no Brasil e acolá por outros continentes do globo terrestre) e de tempos de outrora e da atualidade e narrativiza de modo singular em O Conto da Aia. Os acontecimentos factuais que elencamos neste texto são apenas alguns de inúmeros que mostram como os discursos se constroem em redes que desconhecem fronteiras. Promotores de justiça, juízes, Presidente da República Federativa do Brasil inscrevem-se, pois, em posicionamentos discursivos misóginos que circularam e circulam em diversas sociedades.

Na narrativa de Atwood, as Aias usam um manto de cor vermelha que cobre todo o corpo. Sobre a cabeça, há um tipo de chapéu branco que as impedem de enxergar as laterais, apenas olham para frente. $\mathrm{O}$ vermelho não é sem motivo: ele torna as Aias facilmente vistas, dificultando eventuais fugas. A cor vermelha é também relacionada ao pecado, ao sexo, à queda moral e pecaminosa, ao sangue nos partos e é a cor que representa a carne. O vermelho inscreveas como pecaminosas e como lembrete constante das suas fertilidades. São pecadoras e culpadas a serviço da garantia da existência futura da espécie humana.

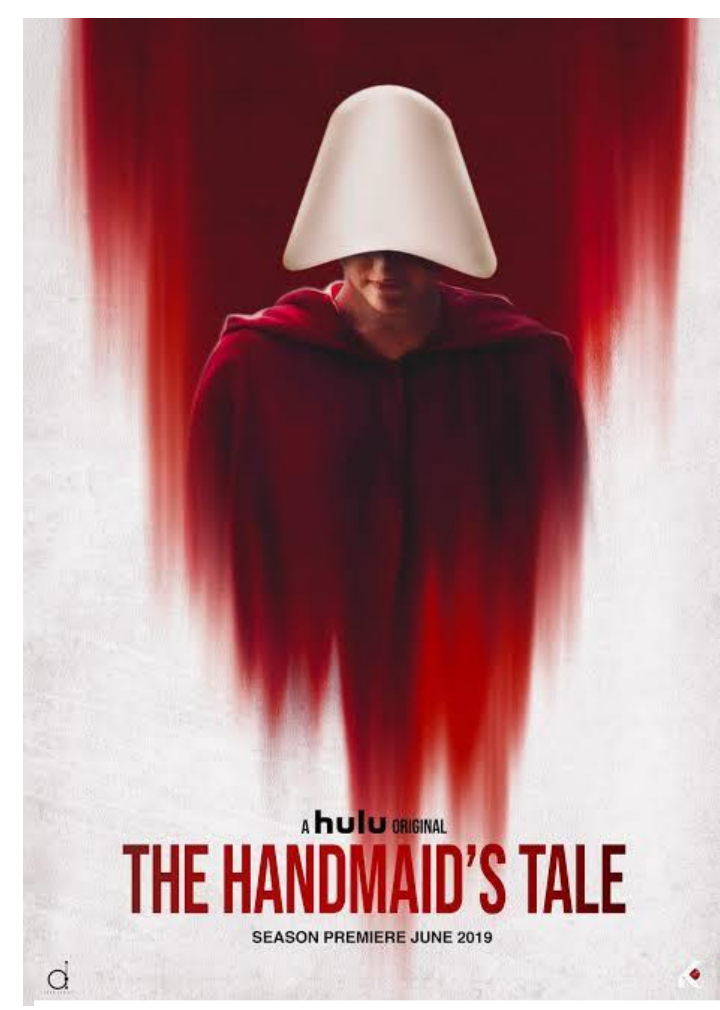

Figura 1: Pôster da terceira temporada elaborado por comunidade de fãs da Série The Handsmaid's Tale. 
A chegada da menstruação é o tormento para as Aias, pois informa a não fecundação e, consequentemente, o não cumprimento do papel a elas designado. O vermelho do sangue é a representação do seu maior fracasso. Mas, na imagem do pôster da terceira temporada de The Handsmaid's Tale (Figura 01), esse vermelho significa ainda o sangue da luta. A união de mulheres de diferentes castas em prol de uma luta comum.

Acontece aqui mais um trocadilho com o nome da protagonista Offred: pode significar também $O f$-red (do vermelho, em tradução livre), aquela que abraça sua própria carne e seu próprio pecado. Na série, não no livro, a personagem tem uma fala extremamente forte e assim se refere ao uniforme: "Nunca deveriam ter nos dado uniformes se não queriam que fôssemos um exército" (THE HANDMAID’S TALE, 2017).

O momento no qual acontece o ato sexual entre a esposa, comandante e a aia é denominado cerimônia - entre os três porque há um papel sendo desempenhado por cada componente nesse momento. Sobre a cama, a esposa Serena Joy se posiciona com as pernas abertas e, entre elas, a Aia se deita recostando a cabeça sobre o seu peito. Tanto a Aia quanto a esposa estão vestidas. Serena levanta os braços de Offred e segura suas mãos representando com esse ato um só corpo, um único ser, caso alcance o objetivo, o produto lhe pertence. $\mathrm{O}$ comandante, até então, não estava no local. A porta se abre e o comandante Fred entra no quarto e se posiciona. Abre as pernas da Aia e sobe sua saia vermelha até a altura da cintura. Abaixa o zíper da calça. Inicia-se então o ato da cerimônia:

Minha saia vermelha é puxada para cima até minha cintura, mas não acima disso. Abaixo dela o Comandante está fodendo. O que ele está fodendo é a parte inferior de meu corpo. Não digo fazendo amor, porque não é o que ele está fazendo. Copular também seria inadequado porque teria como pressuposto duas pessoas e apenas uma está envolvida. Tampouco estupro descreve o ato: nada está acontecendo aqui que eu não tenha concordado formalmente em fazer. Não havia muita escolha, mas havia alguma, e isso foi o que escolhi. (ATWOOD, 2017, p.114)

Beijar é proibido entre nós. Isso faz com que seja suportável. A gente se desliga, se distancia. A gente representa. Ele goza finalmente, com um gemido abafado como se de alívio. Serena Joy, que esteve prendendo a respiração, a expele. O Comandante que esteve se apoiando em seus cotovelos, mantendose afastado de nossos corpos combinados, não permite a si mesmo afundar e mergulhar em nós. Ele descansa um momento, retira, faz recuar, dá sumiço e fecha o zíper. Dá um cumprimento de cabeça, então gira nos calcanhares e sai do quarto, fechando a porta com cuidado exagerado atrás de si, como se nós 
duas fôssemos sua mãe enferma. Há alguma coisa de hilariante nisso, mas não ouso rir. Serena Joy solta minhas mãos. (ATWOOD, 2017, p. 116)

É visível nessa descrição o comportamento do corpo-objeto. Na verdade, o corpo da Aia é um terreno de passagem, um espaço ocupado entre os dois corpos principais (KRÜGER; MARKS DE MARQUES, 2018). Um corpo que é fundamental a sua presença para a manutenção de um ideal político. Não é diversão, é ato de escravo para a Aia, e até mesmo o comandante está cumprindo com um dever. Neste sentido, não é esperado do corpo uma posição de inerte. "Antes de qualquer coisa, a existência é corporal" (LE BRETON, 2007, p. 7).

Essa significação do corpo como objeto está presente ainda nos dizeres em tom de conselho, relembrados por Offred no momento da cerimônia de casamento da Princesa Vicky , quando ela se recorda que a Princesa Vicky, ao ser entregue em matrimônio a Frederico III da Alemanha, perguntou à sua mãe, a então Rainha Victória do Reino Unido, como seria a noite de núpcias. E, então, a Rainha respondeu: "Feche os olhos, pense na Inglaterra" (ATWOOD, 2017 p. 115).

"Santos dos paus ocos" também são os comandantes. Em uma cena da série, Offred é levada pelo comandante Fred a um local que ela reconhece como um hotel, onde ela se encontrou com o seu marido Looke antes do golpe de estado. Agora, neste local, funcionava um bordel secreto: a casa de Jezabel. As prostitutas geralmente eram mulheres rebeldes, fugitivas, as quais eram dadas a escolha de irem para a casa de Jezabel ou serem enviadas para os trabalhos forçados nas colônias de lixo tóxico. O bordel atende diplomatas estrangeiros, mas também, comandantes do alto escalão de Gilead.

As Jezabéis não são oficialmente aprovadas pelo Governo, pois violam as leis e os principais valores pregados pelo Regime. No entanto, ainda assim, o alto escalão do Governo mantém esse segredo entre si. Frequentam o que eles denominam de "o clube", que alimenta a diplomacia com um mercado de escravidão sexual. Após uma noite com as chamadas não mulheres da casa de Jezabel, os comandantes retornam ao seio familiar do lar, com um discurso de fidelidade, decência, castidade, pureza e recato. Qualquer semelhança com políticos e religiosos brasileiros não é mera coincidência.

\section{A Bíblia em Gilead}

A República de Gilead baseia-se na tradução literal de algumas passagens do antigo testamento da Bíblia cristã. O próprio nome Gilead remete a um antepassado bíblico: Gilead 
era filho de Maqui, neto de Manassés, e, portanto, bisneto de José, filho do patriarca Jacó (a história de Jacó será o centro da fundação ritualística desse novo governo). Este herdou um território montanhoso próximo ao rio Jordão que também levou o nome de Gilead. Essa terra ficou conhecida por seus produtos medicinais e pela preciosidade dos seus bosques. Assim, resumidamente, no hebraico bíblico, Gilead é traduzido como significando "montanha do testemunho", ressaltando a importância de testemunhar os feitos de Deus (DICIONÁRIO BÍBLICO, 2010).

A fertilidade mobiliza a República de Gilead. E, como na sociedade bíblica da era dos patriarcas Abraão, Isaque e Jacó, a infertilidade - sempre atribuída ao sexo feminino - é vista como um castigo de Deus e desonra para a mulher (LIVINGSTON et. al., 2000). Proibidos os serviços de reprodução humana, a inseminação artificial e as clínicas de fertilidade, Gilead legitimou o uso das “mães de aluguel”, encontrando um precedente para tal numa interpretação do livro de Gênesis:

Quando Raquel viu que não dava filhos a Jacó, teve inveja de sua irmã. Por isso disse a Jacó: "Dê-me filhos ou morrerei!"

Jacó ficou irritado e disse: "Por acaso estou no lugar de Deus, que a impediu de ter filhos?"

Então ela respondeu: "Aqui está Bila, minha serva. Deite-se com ela, para que tenha filhos em meu lugar e por meio dela eu também possa formar família". (BÍBLIA SAGRADA, Gêneses 30:1-23)

Em Gilead, o parentesco é tido como heterossexual e gênero e sexualidade são circunscritos à dimensão de uma natureza fixa, tendo como origem um Deus criador. Qualquer desvio das determinações da natureza dada pelo Deus do antigo testamento é entendido como subversão ao Regime. A mulher, como no poema do Menino Jesus de Fernando Pessoa, é reduzida a uma simples mala. Natureza e cultura estão salvaguardadas na clássica dicotomia que nos separa dos não humanos.

Se no mundo fora de Gilead, ainda que indispensáveis por serem produtoras de óvulos, as mulheres são ainda ignoradas nos debates sobre as implicações éticas, legais e emocionais envolvidas na pesquisa sobre biotecnologia da reprodução humana (STOLCKE, 2018), em Gilead a invisibilidade da mulher é levada ao extremo. Elas têm apenas o mérito de serem, de fato, malas. A paternidade biológica em Gilead é o único arranjo possível para instaurar as relações de parentesco. Mulheres podem ser substituídas por Aias, homens não são substituídos por outros mesmo que biologicamente inférteis. 
O par maternidade/paternidade, no entanto, é construído como um reconhecimento legal e social do divino, sem passar necessariamente pelo biológico. Para nós, olhando a partir de nosso terreno reflexivo, ser mãe e ser pai parecia, no entanto, algo mais fluido. Vejamos o caso da filha partilhada por Serena e Offred. Entre elas, há um jogo de relações afetivas que mobiliza mãe biológica e mãe "divina” em um esquema de multiparentalidade que joga com o legal e o clandestino. Vejamos!

Na primeira temporada da série, a relação de Serena e Offred é marcada por altos e baixos. Porém, na segunda temporada, é construída uma relação de cumplicidade. Serena decide quebrar as regras do Regime oferecendo, secretamente, a Aia Offred ao motorista Nick, a fim de aumentar as chances da procriação, após as diversas tentativas com o comandante Fred. Esta "quebra de regras" se torna um segredo em torno do qual inicia a construção de uma cumplicidade. A Aia, finalmente, engravida e, a partir de então, a relação entre Offred e Serena começa a ganhar outros contornos.

Após o nascimento da criança clandestinamente concebida no arranjo Offred-NickSerena, as personagens do núcleo central da trama começam a discutir o papel da mulher no Regime de Gilead. A Aia Offred incentiva Serena a buscar, na reunião de comandantes, o direito para que as mulheres possam ler. Serena reúne-se com outras mulheres da Casta das Esposas para então falar com os comandantes em uma reunião privada. Ao apresentar a questão e ter sua petição rejeitada pelos Comandantes, ela tira uma Bíblia do bolso e lê, sua punição por esse ato foi a amputação de um dos dedos da sua mão. Este fato faz com que Offred problematize ainda mais junto a Serena sobre como seria a filha crescer sob o Regime. Desse diálogo constante entre a Aia e a Esposa, surge a possibilidade de tirar Nicole ${ }^{\mathrm{xiv}}$ (a filha) de dentro da República de Gilead.

O movimento de resistência Mayday surge na Casta das Marthas, é através deste movimento que Serena e Offred planejam uma fuga. A relação de cuidado e libertação de Nicole afirmam os laços de maternidade tanto da Aia quanto de Serena. Nesse ponto, são enfraquecidas as identidades das castas e se sobressai uma estratégia de resistência. Em toda a narrativa, as mulheres não formavam grupos, não eram exércitos, agora, há uma rede de comunicação entres as Castas por meio das Marthas, informações são trocadas, estratégias são elaboradas, planos de rebeliões começam a ser estudados. Em uma dessas estratégias, Offred e Serena entregam Nicole para a Aia Emily que consegue retirar Nicole de Gilead. 
A organização de Castas parece estabelecer regularidade com outro romance publicado em 1932: Admirável Mundo Novo de Aldous Huxley, que também organizava a sociedade em castas chamadas Beta, Gama, Alfa e Y. Salientamos que Margareth Atwood admitiu ter usado essas referências para inspirar a criação do mundo de The handmaid's tale. Além dessa referência, é possível fazer uma outra ligação interessante, o livro de Atwood é publicado no ano de 1985, essa época é o pano de fundo de outra distopia muito conhecida publicada em 1949 escrita por George Orwell, e denominada 1984. Atwood também afirmou ter usado esse texto como inspiração.

Apesar de grande parte do Regime de Gilead estar baseada em passagens bíblicas, principalmente do antigo testamento, há manobras interpretativas dos escritos bíblicos para adequação aos bizarros interesses dos seus líderes políticos. As citações bíblicas são descontextualizadas ou incompletas.

A narradora-protagonista Offred relata que o comandante tem algo que elas não têm, ele tem a palavra. "Como a desperdiçamos, um dia" (ATWOOD, 2017, p. 81), pondera a Aia de Fred.

Na hora do almoço eram as Beatitudes. Bem-aventurado isso bem-aventurado aquilo. Elas punham para tocar uma gravação em disco, a voz era de um homem. Bem-aventurados os pobres de espírito, porque deles é o reino dos céus. Bem-aventurados os misericordiosos. Bem-aventurados os mansos. Bem-aventurados os que se calam. Eu sabia que este último eles tinham inventado, sabia que estava errado, e que tinham excluído partes também, mas não havia nenhuma maneira de verificar. Bem-aventurados os que choram, porque eles serão consolados.

Ninguém disse quando. (ATWOOD, 2017, p.109)

Na sequência discursiva acima, há já ditos dos evangelhos de Mateus (5:3-16) e Lucas (6:20-49). A autora destaca desses textos bíblicos enunciados que são apresentados em $O$ Conto da Aia como recortes, como por exemplo: "bem-aventurados os misericordiosos, porque eles encontrarão misericórdia" (grifo nosso) e, ainda, "Bem-aventurados os mansos, porque eles herdarão a terra" (grifo nosso). Ao não dizer as complementações dos períodos frasais bíblicos com as orações explicativas introduzidas pela conjunção "porque", o sentido que se produz é de que o governo de Gilead suplantava a ideia de misericórdia e de posse da terra. Dizeres que não são ditos uma vez que estes poderiam ter sido utilizadas como combustível para uma resistência que buscasse do governo ações misericordiosas ou, até mesmo, uma demanda pela tomada da posse da terra. Por outro lado, ao acrescentar "bem-aventurados os que se calam", estavam assim instaurando o silêncio necessário para a não rebelião. São citações, destacadas

Revista RBBA Revista Binacional Brasil Argentina 
de seu texto-fonte ${ }^{\mathrm{xv}}$ - o novo testamento da Bíblia cristã - para dar ao regime Gilead poder de aceitação, mas, como o texto bíblico não corresponde, em sua íntegra, aos sentidos de repressão desse Regime, é necessário transformar, recortar e até acrescentar enunciados.

Apesar de ser uma sociedade dita cristã, os nomes Cristo, Jesus, Pedro, João, Maria ou qualquer outro personagem do novo testamento não são citados no livro, com exceção do apóstolo Paulo, em uma única ocorrência, porém em um contexto bem curioso, que retomamos mais à frente.

Há um evento chamado de Razavagâncias que pode acontecer tanto para castas masculinas (quando os exércitos alcançam vitórias) quanto para femininas (usadas para que as freiras abjurem seus votos). A maioria das freiras vive na clandestinidade, mas muitas são descobertas pelo Regime. Quando são já avançadas em idade são mandadas para as colônias, porém as que ainda são jovens e férteis eles tentam "converter". As convertidas, passam por uma cerimônia pública diante de todas as Aias, renunciam ao celibato e assim aceitam o véu vermelho em prol do bem comum. As freiras nunca se tornam da Casta das Esposas, são consideradas perigosas demais para estarem tão perto dos membros do alto escalão de Gilead.

Nesse sentido, é possível compreender que, apesar de ser uma sociedade cristã, não é de confissão cristã Católica Apostólica Romana, pois os praticantes dessa confissão deveriam se converter a esse "novo cristianismo" e, mesmo depois de "convertida", não poderia exercer ou participar de uma casta que lhe empregasse algum tipo de privilégio, porque ainda eram consideradas perigosas. Nem as próprias Aias se sentem à vontade na presença dessas pessoas convertidas.

Outra abordagem de grupos cristãos está no relato do "muro", local onde transgressores das leis do Regime são mortos enforcados e expostos até o estado de putrefação para servirem de exemplo. Nesse muro, em uma determinada ocasião, havia dois dependurados: um era católico com uma cruz de cabeça para baixo e o outro tinha apenas um "J" em vermelho.

A protagonista diz que o "J" não significa judeu, geralmente os judeus são identificados com estrelas amarelas. Para o Regime, os judeus são considerados filhos de Israel e, portanto, a eles é dada uma escolha: converter ao Regime ou emigrar de volta para Israel. A narradora fala que muitos optaram por emigrar e foram postos em navios sendo deportados de volta à terra de Abraão, em Jerusalém. A narrativa desse fato termina com a seguinte afirmação "se pudermos acreditar nos noticiários". No entanto, o livro O Conto da Aia tem uma particularidade, um posfácio chamado Notas Históricas Sobre O Conto da Aia. Nela, há uma Revista RBBA $\mid$ Revista Binacional Brasil Argentina 
apresentação de um palestrante no décimo segundo simpósio sobre estudos gileadeanos no ano de 2195, bem depois da queda da República de Gilead. No simpósio o palestrante afirma:

Os Territórios Nacionais e o plano de embarcar em navios as pessoas de religião judaica foram ambos dele, bem como a ideia de privatização do esquema de repatriação dos judeus, com o resultado de que mais de uma carga inteira de navio lotado de judeus foi simplesmente atirada no Atlântico, para maximizar os lucros. (ATWOOD, 2017 p361).

Seguindo a leitura do relato anterior, é possível perceber ainda que não se trata de um ramo do protestantismo conhecido, visto que, ao analisar que o "J" não era de um judeu, Offred se pergunta: "De modo que o J não é de judeu. O que poderia ser? Testemunha de Jeová? Jesuíta? Seja lá o que significasse, está morto do mesmo jeito” (ATWOOD, 2017, p. 238).

A cruz invertida pode trazer referência tanto à morte do apóstolo Pedro que, ao ser julgado em Roma e condenado à crucificação, afirmou não ser digno de morrer como Cristo, sendo então crucificado de cabeça para baixo. Mas também pode ser feita uma referência a um símbolo do anticristo utilizado nas eras medievais, representando as forças do mal, diabo e a negação aos dogmas cristãos (DICIONÁRIO DE SIMBOLOS, 2019).

Uma última menção às citações alteradas do texto escrito na Bíblia e recontextualizadas conforme os interesses do Regime está nesta sequência:

Que cada uma dê, diz o slogan, de acordo com sua capacidade; para cada um de acordo com suas necessidades. Recitávamos isso, três vezes, depois da sobremesa. Era da Bíblia, ou pelo menos diziam que era. São Paulo de novo, em Atos. (ATWOOD, 2017 p. 143)

Há aqui dois equívocos. O primeiro deles é a autoria do livro de Atos, atribuída ao apostolo Paulo, quando este foi escrito por Lucas. O segundo é que a citação acima não está na Bíblia. A própria Margareth Atwood traz uma nota de rodapé no livro esclarecendo a autoria da mensagem: "Na verdade uma releitura machista de uma citação de Marx (1875)." (ATWOOD, 2017 p. 143).

No entanto, é importante dizer que não se pode "passar a régua" e medir todos os cristãos, seja ele de qualquer segmento, numa mesma medida e num mesmo discurso. Existem ainda cristãos que prezam pelo discurso de Cristo e que compreendem, assim como o reformador Martinho Lutero, que o discurso cristão é tolerante e não extremista, que não fazem negociatas com a fé nem precisam do uso de armas para apregoar a paz (LUTERO, 1993),

Revista RBBA Revista Binacional Brasil Argentina 
muitas vezes esses não estão nos meios midiáticos, mas, ainda assim, fazem a diferença onde estão.

Judith Butler, em sua obra mais recente, trata do que chama de igualdade radical $^{\mathrm{xvi}}$. A partir do momento em que entendemos a interdependência que existe entre todas as pessoas, é possível perceber que a preservação da vida do outro é importante. Na ética cristã, a não violência é uma condição fundamental dos ensinamentos de Cristo. O Amor radical no escopo da fé cristã é o que torna essa não violência possível. Essa perspectiva nos faz questionar os tempos distópicos de coronavírus em que vivemos, se esse Amor Radical discutido por Butler e base da ética cristã realmente existisse no governo atual, que tanto fala em Deus, o presidente Jair Bolsonaro não faria um pronunciamento dizendo que a morte de mais de duas mil pessoas não importam frente ao colapso econômico que ainda virá.

\section{0 puritanismo em Gliead: Margareth Atwood e o Conto da Aia}

A construção da obra de Margareth Atwood, em 1985, aconteceu em um momento de expansão de programas cristãos na televisão. O enredo do Conto da Aia evidencia grandes semelhanças com os movimentos puritanos ocorridos na Inglaterra durante a época da Rainha Elizabeth I, por volta dos anos 1560. Esse movimento reformista tinha um descontentamento pela igreja inglesa Anglicana por esta ainda manter rituais, cerimônia e hierarquias que remontavam ao catolicismo (RIKEN, 1992).

Não é fundamental para esse trabalho detalhar o movimento puritano e seus dogmas, no entanto, é importante mencioná-lo por conta da influência dessa construção no contexto de Gilead. Esse movimento chega aos Estados Unidos e Canadá que foram há muito tempo colônias da Inglaterra, sendo que, até hoje, o Canadá faz parte da Commonwealth que tem a Rainha Elizabeth II como monarca soberana (SILVA, 2018).

A sociedade puritana era bastante zelosa em sua interpretação bíblica e as mulheres eram submetidas à total obediência aos pais e maridos. Eram intolerantes em relação aos grupos negros, indígenas e outros cristãos, como os católicos e os anglicanos ritualistas. É por conta dessa visão conservadora e fundamentalista que os puritanos participam, em outubro de 1692, do episódio da caça às bruxas no povoado de Salém, Massachussets nos EUA. Cerca de 150 pessoas foram presas e vinte delas executadas sob acusações de bruxaria, a maioria mulheres. A escritora Margareth Atwood é descendente de puritanos, sendo que uma de suas ancestrais 
estava entre as condenadas no julgamento de Salém. A autora dedica o livro O Conto da Aia a essa ancestral chamada Mary Webster (SILVA, 2018).

Assim, ao analisar o cristianismo apresentado em O Conto da Aia, Margareth Atwood traz no seu âmago essa relação com o puritanismo e suas ações à época de 1692, além ainda de também ter se inspirado na revolução islâmica instituída no Irã em 1979, quando o regime monárquico do Xá Mohammad Reza Pahlevi foi deposto pelo fundamentalismo religioso com a criação de um estado totalitário e teocrático sob o comando do Aiatolá Ruhollah Khomeini (SILVA, 2018).

É dessa forma que esse mundo distópico de O Conto da Aia ganha formas, mostrando em detalhes a instauração de um regime totalitário e teocrático. O golpe de estado, manipulação dos textos bíblicos, cerceamento de direitos e, por fim, o silêncio. Ao observar essas etapas características da distopia de Margareth Atwood, percebe-se que esse mundo imaginado pela autora não é tão distópico assim. Na realidade, é um mundo bem possível. Não é incomum encontrar "ditos cristãos", hoje em dia na mídia, também manipulando textos bíblicos para atender interesses próprios, discursos que se distanciam do ideário pregado por Cristo, e se aproximam cada vez mais de interesses partidários e políticos do que da fé.

A romancista reuniu no Conto da Aia fatos ocorridos em diferentes momentos da história da humanidade, sendo que, muitos deles, se repetem em nossos dias, para dar contornos à Republica de Gilead. Preconceitos instaurados e opressões diversas deste Regime não são novidades. No posfácio do livro, o palestrante, anteriormente mencionado, diz:

Suas políticas racistas, por exemplo, estavam firmemente enraizadas no período pré-Gilead, e temores racistas forneceram parte do combustível emocional que permitiu que o golpe de Gilead para a tomada do poder fosse tão bem-sucedido quanto foi. (ATWOOD, 2017, p. 358).

Os regimes políticos instaurados nestes últimos anos merecem o nosso olhar cuidadoso. Os preconceitos aí existentes não são novidades de um político "sem papas na língua”, mas sim manifestações de um grupo de eleitores que já possuíam tais ideias e, agora, finalmente, acharam seu representante destemido. O problema não pode ser pensado apenas quando esses governos “distópicos" ganham o cenário político e instauram o poder, mas na não resistência a eles, que, aos poucos, tem se tornado costumeiros, como dizia Tia Lydia ${ }^{\text {xvii. }}$.

Pereira (2018) destaca que o romance O Conto da Aia foi escrito em um momento de política reacionária, o governo Reagan havia promovido diversas privatizações, o afrouxamento Revista RBBA $\mid$ Revista Binacional Brasil Argentina 
de direitos relacionados à classe trabalhista, aumento nos gastos militares, cortes em gastos públicos, além ainda de ser um período no qual grupos políticos defendiam valores familiares tradicionais, posicionando, por exemplo, contra leis relacionadas ao aborto e aos direitos homossexuais, acrescentando ainda a essa lista a organização política de cristãos conservadores e programas televisivos de cunho evangélico. Tal contexto histórico justifica a afirmação da autora Atwood (2017) ao dizer que não colocaria no livro eventos que não tivessem já acontecido no "pesadelo" da história, nem uma tecnologia que não estivesse já disponível. É por esse aspecto que Varsam (2003) caracteriza o romance como uma distopia concreta. Ou seja, a linha entre ficção e realidade é mais tênue do que se pode imaginar.

O que não se sabia é que essa linha ficaria cada vez mais tênue com o passar dos anos. Ana Rüsche (2017) traz um relato bem interessante sobre essa ascensão de governos com o resultado da eleição do presidente Donald Trump nos Estados Unidos. Segundo ela, quando a apuração dos votos demonstrava uma inúmera quantidade a favor de Trump, nas telas de televisão de um bar, "uma senhora com cabelos revoltos e casaco elegante berrava contra os números: Não é possível! Não é possível!". No dia seguinte, nas manifestações que se seguiram pelo país, um cartaz em especial lhe chamou a atenção: "Por favor, façam Margaret Atwood, voltar a ser ficção de novo".

Sobre a ascensão de Gilead, Offred chega a narrar que não há nenhum movimento coletivo de resistência nos Estados Unidos, quando os filhos de Jacó suspenderam a constituição, alegando ser essa uma ação temporária, não houve tumultos na rua. Não foi uma mudança instantânea, mas paulatina e sem resistência.

Nada muda instantaneamente: numa banheira que se aquece gradualmente você seria fervida até a morte antes de se dar conta. Havia matérias nos jornais, é claro. Corpos encontrados em valas ou na floresta, mortos a cacetadas ou mutilados, que haviam sido submetidos a degradações, como costumavam dizer, mas essas matérias eram a respeito de outras mulheres, e os homens que faziam aquele tipo de coisas eram outros homens. (ATWOOD, 2017, p. 71).

No livro, Offred diz que, nos primeiros momentos, as Tias do Centro Vermelho não eram de conhecimento público, assemelhando assim com os relatos, por exemplo, da população alemã que afirmavam não ter conhecimento algum dos campos de concentração nazistas.

Era tudo secreto inicialmente, por trás de cercas de arame farpado. Poderiam ter havido objeções ao que estavam fazendo, mesmo então. De maneira que embora as pessoas tivessem visto uma Tia aqui e ali, não sabiam para que elas serviam realmente. Devem ter pensado que fossem algum tipo de enfermeira 
do exército. As pessoas já haviam parado de fazer perguntas, a menos que de fato precisassem. (ATWOOD, 2017, p.291).

Para Rüsche (2017), poucas obras traduzem tão bem o que se assiste na era atual. A maior potência econômica mundial, os Estados Unidos, elegendo um presidente abertamente misógino. E porque manter esse pensamento apenas no governo Trump? Em 2018, uma senhorinha em algum bar brasileiro também berrou contra os números que elegeram um presidente abertamente racista, misógino e homofóbico.

Como Offred diz na sua narrativa, o governo dos Filhos de Jacó estava estampado nas mídias e a população não se deu conta do que orbitava à sua volta. Outro questionamento presente num livro de não ficção, mas sim biográfico, "A mulher do oficial Nazista" de Edith Hahn Beer. Beer também relata que a população não se deu conta do que significava a ascensão do partido Nazista e muitos não arianos começaram a se questionar: "Como uma gangue de homenzinhos pomposos consegue destruir tão rapidamente as instituições democráticas de um grande país?” (BEER, 2017, p.39). O ideário de que a história se repete, aqui se enquadra, não mais na ficção, mas com certeza essa tem sido a pergunta feita por muitos brasileiros e norte americanos nos governos atuais.

\section{Considerações finais}

A obra de Atwood traz temas das agendas feministas, discussões ecológicas, religiosas, políticas, direitos de minorias, gênero, dentre outras. Discussões essas que estiveram e estão no centro das agendas eleitorais nos últimos anos e, por isso, não se pode estar alheio a elas, afinal, como defende a protagonista em estudo, "nada acontece instantaneamente".

O Conto da Aia nos convida a renunciar as diversas práticas de opressão que fizeram as histórias dos estados-nações para desejarmos novas formas de fazer e contar a história. Formas que reconheçam as diversas manifestações de vida, para, como Butler (2003) nos ajudar a pensar, além dos lugares da legitimidade e da não legitimidade dos regimes políticos.

Esperamos que os povos de todos os lugares do planeta possam se unir em práticas de parentesco e amizade das mais diversas e que elas sejam capazes de dar um basta à onda conservadora que ameaça o planeta. O coronavírus de 2019-2020 não nos deixará esquecer isso. Que possamos, ainda que, em ameaças de desaparecimento da espécie humana e nos medos delas decorrentes, agir em laços de solidariedade capazes de fazer nascer, criar e cuidar de crianças, estabelecer vínculos emocionais, cuidar da vida, da doença e da morte, buscando, nos 
termos das reflexões de Butler (2003) sobre o casamento gay, possibilidades de reconhecimento na sociedade civil e na vida para além do Estado.

Precisamos romper com a ideia de parentesco cultivada pelos comandantes do Conto da Aia, Jair Bolsonaro e Carla Zambelli para pensar em como as nossas relações afetivas em uma determinada comunidade. Como pontuou Butler (2003), novas relações de parentesco põem em questão a distinção entre parentesco e comunidade, ou reivindicam novos entendimentos sobre a amizade. Assim laços duráveis poderão ser pensados fora do casamento e oferecerão possibilidades de vínculos não necessariamente redutíveis à família nucelar.

\section{REFERÊNCIAS}

ATWOOD, Margareth. O conto da Aia. Tradução Ana Deiró. Rio de Janeiro: Rocco, 2017. Tradução de: The Handmaid's Tale.

BEER, Edith Hahn. A mulher do Oficial Nazista. Tradução Natalie Gerhardt. Rio de Janeiro: Harper Collins, 2017.

BÍBLICO, D. Dicionário Bíblico Ilustrado: Crescer. 1. ed. Santo André: Geográfica, 2010.

BUTLER, Judith. Regulações de gênero. Cad. Pagu, Campinas , n. 42, p. 249-274, jun. 2014. $260,2003$.

O parentesco é sempre tido como heterossexual?. Cad. Pagu, Campinas, n. 21, p. 219-

DINIZ, Debora. Zika: do sertão nordestino à ameaça global. Rio de Janeiro: Cibilização Brasileiro, 2016.

FEITAL, Yasmine. et al. The Handmaid's Tale: A Representação Da Mulher Na Série E A Proximidade Com A Realidade Brasileira. In: ALMEIDA, F. F. de (org.). XXIII Congresso de Ciências da Comunicação na Região Sudeste. Belo Horizonte, MG, 2018. p. 1 - 15.

JUSBRASIL. Um em cada três brasileiros culpa as mulheres por estupro, diz pesquisa. 2019. Online. Disponível em: https://examedaoab.jusbrasil.com.br/noticias/386291560/ umem-cada-tres-brasileiros-culpa-as-mulheres-por-estupro-diz-pesquisa. Acesso em: 05 de agosto de 2019.

KRÜGER, Luana de Carvalho; MARKS DE MARQUES, Eduardo. O corpo-objeto em O Conto da Aia - a desperformatização do corpo da mulher no universo distópico do romance. In: CUNHA, Andrei dos Santos; FERREIRA, Cinara; NEUMANN, Gerson Roberto; BITTENCOURT, Rita Lenira. (Org.). Ilhas Literárias - Estudos de Transárea. Porto Alegre: Editora do Instituto de Letras UFRGS, 2018. 
LIVINGSTON, George Hebert; COX, Leo G; KINLAW Dennis F; BOIS, Lauriston. J. Du; FORD, Jack; DEASLEY, A. R. G. Comentário Bíblico Beacon: Gênesis a Deuteronômio. 1. ed. Rio de Janeiro: CPAD, 2000. v. 1.

LUTERO, Martinho. Martinho Lutero Obras Selecionadas: Debates e Controvérsias II. Rio Grande do Sul: Sinodal, 1993. v. 6.

MAINGUENEAU, Dominique. Citação e Destacabilidade. In: MAINGUENEAU, D. Cenas da Enunciação. Organização: POSSENTI, S. e SOUZA-E-SILVA, Maria Cecília Pérez. São Paulo: Parábola Editorial, 2008.

MAINGUENEAU, Dominique. Gênese dos discursos. Curitiba/PR: Criar, 2007. [1984].

PEREIRA, Alice de Araújo Nascimento. Circulação, Tramas \& Sentidos na Literatura. In: XVI CONGRESSO INTERNACIONAL DA ASSOCIAÇÃO BRASILEIRA DE LITERATURA COMPARADA (ABRALIC), XVI. 2018. Anais...Brasília, 2018. 3090$3106 \mathrm{p}$.

RÜSCHE, Ana. Atwood e de quanto o real ultrapassa a ficção: A obra da escritora canadense como lente para pensarmos o ano que acaba. Pernambuco. Pernambuco, v. 142, p. 1217, Dez 2017.

SAGRADA, Bíblia. (Almeida Revista e Atualizada, Trad). Barueri, SP: Sociedade Bíblica do Brasil, 2017a.

SILVA, Alane Melo da. A woman's place: Uma análise comparativa da personagem Serena Joy do livro para as telas. Transversal - Revista em Tradução, Fortaleza, v. 4, n. 8, p. 31 42, Ago 2017.

SÍMBOLOS, Dicionário. de. A cruz invertida. 2019. Disponível em: https: //www.dicionariodesimbolos.com.br/cruz-invertida/. Acesso em: 08 de agosto de 2019.

STENGERS, Isabelle. No tempo das catástrofes: resistir à barbárie que se aproxima. São Paulo: Cosac Naify, 2015.

STOLCKE, Verena. Homo clonicus: Nuevas técnicas, viejas ideas de engendrar humanos. Revista de antropología social y cultural Etnografías Contemporáneas, San Martíns, $\mathrm{n}^{\circ}$ 6, p. 45-65, 2018.

THE Handsmaids’tale - Night. Bruce Miller. EUA: Hulu, 2017. Série.

VARSAM, Maria. “Concrete Dystopia: Slavery and Its Others”. In: BACCOLINI,

Raffaella; MOYLAN, Tom (orgs.). Dark Horizons: Science Fiction and the DystopianImagination. Nova York; Londres: Routledge, 2003. 


\section{SOBRE OS AUTORES}

Eloísa Cecília Dias Martins é Mestranda em Ensino, Linguagem e Sociedade pela Universidade do Estado da Bahia e Especialista em Perícia e Auditoria Ambiental pelo Centro Universitário Internacional. É membro líder do Grupo Ensino, Discurso e Sociedade. Tem experiência na área de Ecologia e Zoologia (Levantamento de Anurofauna) e em Educação.

Endereço eletrônico: elocecilia2@ hotmail.com

ORCID: https://orcid.org/0000-0002-1422-7279

Elizeu Pinheiro da Cruz é Doutor em Ciências Sociais pela Universidade Federal da Bahia e Professor do Programa de Pós-Graduação em Ensino, Linguagem e Sociedade da Universidade do Estado da Bahia (UNEB de Caetité, Bahia). É líder do Grupo Ensino, Linguagem e Sociedade. Tem interesse por ciências biológicas e ciências sociais, atuando principalmente nos seguintes temas: etnografia da prática científica, discursos sobre a biodiversidade da caatinga, sexualidade, gênero e ciência, história do ensino de ciências e formação de professores.

Endereço eletrônico: elizeuprof@gmail.com

ORCID: https://orcid.org/0000-0003-1454-6832

Sidnay Fernandes dos Santos é Doutora em Linguística pela Universidade Federal de São Carlos e Professora do Programa de Pós-Graduação em Ensino, Linguagem e Sociedade da Universidade do Estado da Bahia (UNEB de Caetité, Bahia). É líder do Grupo Ensino e do Grupo Ensino, Discurso e Sociedade. Tem experiência na área de Linguística, com ênfase em Análise do Discurso.

Endereço eletrônico: sidnayfernandes@ hotmail.com

ORCID: https://orcid.org/0000-0001-5932-4948

\section{Notas}

${ }^{i}$ Disponível em: < https://g1.globo.com/bemestar/coronavirus/noticia/2020/03/20/mais-de-10-mil-mortes-porcovid-19-no-mundo-diz-universidade.ghtml > Acesso em: 22 de mar. De 2020.

ii "Eva", composição de Giancarlo Bigazzi e Humberto Tozzi.

iii A antropóloga Debora Diniz (2016) investigou o zika vírus no nordeste brasileiro, tendo como sujeitos da sua pesquisa mulheres, médicos e cientistas, e rastreou as manifestações iniciais desta doença, também transmitida pelo Aedes aegypti, que provocou a redução da circunferência da cabeça nos bebês nascidos de mães acometidas pela patologia. A biografia do zika produzida por Debora Diniz é, sem dúvida, uma forte inspiração para o Grupo de Pesquisa Antropologia, Corpo e Ambiente (UNEB/CNPq), vinculado ao Núcleo de Pesquisa Ensino, Discurso e Sociedade (Núcleo DisSE), do qual somos integrantes, reunir esforços iniciais para mapear o cenário do coronavírus no sertão da Bahia.

iv Disponível em <https://blogdaboitempo.com.br/2020/03/20/judith-butler-sobre-o-covid-19-o-capitalismo-temseus-limites/> Acesso em 22 de mar. 2020. 
v "Pegar visão" é uma gíria baiana enunciada geralmente quando alguém, repentinamente, entende algo sobre alguma coisa. No áudio do WhatsApp, o flanelinha utiliza essa expressão para falar de seu isolamento social.

vi Outra gíria muito usada na Bahia que significa resolver um problema de modo prático e rápido.

vii Com Samba-Enredo intitulado "A Verdade Vos Fará Livre”, a Mangueira levou para o sambódromo de 2020 um samba engajado na problematização da política brasileira.

viii Insistimos nesta entrada com uma reflexão sobre a COVID-19 porque, a nosso ver, ela explicita o quanto as respostas do grupo político que ocupa a Presidência da República Federativa do Brasil e de muitos empresários em defesa do "salvemos a economia" indicam como o mundo tem sido um lugar defeituoso. Homens do poder político e econômico estão, frente à pandemia associada à COVID-19, mais interessados em lucros do que em proteger a vida de idosos e imunodeprimidos. Neste sentido, entendemos que há uma ligação entre COVID-19 e O Conto da Aia, alvo principal deste texto, que merece uma especial atenção.

ix Todas as vezes em que aparecem referências a mulheres, recusaremos o esquema de citação da ABNT por entender que ele apaga as mulheres da produção científica ao citar apenas o último sobrenome, geralmente "o nome do pai".

${ }^{x}$ Casta não muito explicada na série. No livro, não aparece esse termo, mas sim o termo econoesposas e, também, não se apresenta uma explicação mais detalhada sobre essa casta. No entanto, partindo da abordagem da série, pode-se dizer que são pessoas de baixa renda e que não se encaixam nas funções das demais castas.

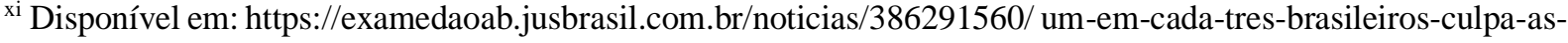
mulheres-por-estupro-diz-pesquisa.

xii Disponível em: https://www.conjur.com.br/2017-set-12/ academia-policia-ejacular-publico-importunacaocultura-estupro.

xiii Disponível em: https://extra.globo.com/noticias/brasil/jair-bolsonaro-repete-insulto-deputada-maria-dorosario-so-nao-te-estupro-porque-voce-nao-merece-14781338.html.

xiv Nicole é o nome que Serena escolhe para a filha que a Aia cladestinamente teve com Nick em um encontro organizado por ela, por Serena. Nome que incialmente foi rejeitado por Offred. Ao assistir à série, ficamos pensado em tal ato como uma provocação ao seu esposo, Fred, que terá uma filha de outro homem (Of Nick, de Nick). Durante uma tentativa de fuga de Offred, ela entrega a sua filha a Emily (Aia que, na ocasião, fugia para o Canadá) e decide ficar em Gilead para encontrar a sua outra filha (que teve antes do Regime com o esposo que, na ocasião, já estava no Canadá). Offred fala para a parceira de fuga chamar a bebê de Nicole, como se naquele instante, quando a fuga do Regime já é algo concreto, tivesse aceitado uma espécie de maternidade compartilhada ou, simplesmente, desdenhasse da possibilidade de infertilidade do comandante Fred. Diferente da troca exclusiva de mulheres como preconizado na antropologia estrutural, outras formas de trocas surgem mesmo em regimes autoritários, oferendo condições para que modos distintos e não hegemônicos de parentesco apareçam.

xv Teorizações desenvolvidas por Maingueneau. Sugerimos ao leitor, como introdução ao tema, o texto Citação e Destacabilidade publicado na obra Cenas da Enunciação (2008).

${ }^{\mathrm{xvi}}$ Essa discussão é apresentada no livro The Force of Non-Violence: An Ethico-Political Bind De Judith Butler a ser publicado em 2020. Um comentário sobre a obra está disponível em https://outraspalavras.net/outrasmidias/judith-butler-propoe-nao-violencia-agressiva/..

xvii “'O costumeiro, dizia Tia Lydia, é aquilo a que vocês estão habituadas. Isso pode não parecer costumeiro pra vocês agora, mas depois de algum tempo será. Irá se tornar costumeiro” (ATWOOD, 2017 p46).

Recebido em: 28/04/2020

Aprovado em: 28/05/2020

Publicado em: 01/07/2020 